\title{
Does expiratory flow limitation predict chronic dyspnoea in adults with cystic
}

\section{fibrosis?}

\author{
A.E. Holland*,\#, L. Denehy\# and J.W. Wilson ${ }^{\top,+}$
}

ABSTRACT: Tidal expiratory flow limitation (EFL) may promote dynamic hyperinflation and contribute to chronic dyspnoea. The purpose of this study was to assess the contribution of EFL to chronic dyspnoea in adults with cystic fibrosis (CF).

The presence of EFL was determined in 102 adults with stable CF (forced expiratory volume in one second (FEV 1 17.3-91.5\% predicted) and 20 age-matched control subjects using the negative expiratory pressure technique. Measurements of inspiratory capacity (IC) and spirometry were performed, and chronic dyspnoea was evaluated using the modified Medical Research Council scale.

EFL was present in 34 subjects (33\%), with 18 subjects flow limited in the sitting position and 16 subjects flow limited only in the supine position. Flow limitation in the sitting position was associated with older age and lower FEV 1 compared with flow-limited supine position and nonflow-limited subjects. A significant reduction in IC accompanied EFL in both the sitting and supine positions. Flow limitation in the sitting position was associated with significantly higher levels of chronic dyspnoea. Ordinal regression analysis indicated that EFL was the best predictor of chronic dyspnoea in a model that included FEV $1 \%$ pred.

Expiratory flow limitation in cystic fibrosis is associated with reduced forced expiratory volume in one second, older age and dynamic hyperinflation. Expiratory flow limitation significantly contributes to chronic dyspnoea in cystic fibrosis.

\section{KEYWORDS: Cystic fibrosis, dyspnoea, respiratory function tests}

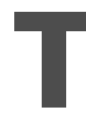
idal expiratory flow limitation (EFL) refers to a condition in which maximal expiratory flow is generated during quiet breathing at rest. Tidal EFL has been associated with dynamic hyperinflation during tidal breathing [1], where end-expiratory lung volume is greater than the relaxation volume of the respiratory system. Although this reduction in inspiratory capacity (IC) serves to increase expiratory flow, it may also result in increased inspiratory work and impaired inspiratory muscle function $[2,3]$. This response to tidal EFL plays an important role in the pathogenesis of chronic dyspnoea in chronic obstructive pulmonary disease (COPD) [4].

The prevalence of EFL in adults with cystic fibrosis (CF) is unclear. Previous studies have concluded that the prevalence of EFL is low [5-7]; however, the inclusion of a small number of subjects, their relatively mild disease and young age may have influenced these findings. In addition, EFL was not evaluated in the supine position $[5,7]$ where it may manifest earlier in the disease process due to reduced functional residual capacity (FRC) with recumbency and a resulting decrease in expiratory flow reserve [8]. No study has determined the relationship of tidal EFL to chronic dyspnoea in CF. It is likely that EFL has significant clinical implications in $\mathrm{CF}$, as two of the most important treatments, exercise and chest physiotherapy, rely on the ability to increase expiratory flow rates $[9,10]$.

The aims of this study were: 1) to determine the prevalence of EFL in adults with $\mathrm{CF}$; 2) to describe the characteristics of EFL in CF, including the relationship of EFL to dynamic hyperinflation; and 3) to determine the relationship of EFL to chronic dyspnoea in adults with CF.

\section{METHODS}

\section{Subjects}

A total of 102 consecutive patients aged $\geqslant 18$ yrs with stable disease [11] were recruited from a CF clinic at a university teaching hospital. In addition to this, an advert was used to recruit a

\section{AFFILIATIONS}

Depts of *Physiotherapy and

"Allergy, Immunology and

Respiratory Medicine, Alfred Hospital,

\#School of Physiotherapy, University of Melbourne,

+Dept of Medicine, Monash

University, Melbourne, Australia

CORRESPONDENCE

A. Holland

Dept of Physiotherapy

Alfred Hospital

Commercial Rd

Melbourne 3004

Australia

Fax: 61392762702

E-mail: a.holland@alfred.org.au

Received:

October 182005

Accepted after revision:

March 052006

SUPPORT STATEMENT

This study was supported by the William Buckland Foundation

Medical Research and Technology in Victoria Program and the National Health and Medical Research Council Dora Lush Scholarship. 
further 20 control subjects without a history of lung disease. Subjects were excluded if they had a history of obstructive sleep apnoea or upper airway obstruction. The study was approved by the institutional ethics committee at the Alfred Hospital and University of Melbourne (Melbourne, Australia).

\section{Measurements}

Measurement of tidal EFL was performed using the negative expiratory pressure (NEP) technique [4]. The experimental setup consists of a vacuum generator and pneumotachograph (MicroNEP; Micro Medical, Kent, UK). After a period of relaxed tidal breathing, NEP of $-5 \mathrm{cmH}_{2} \mathrm{O}$ was applied when expiratory flow reached a threshold value of $30 \mathrm{~mL} \cdot \mathrm{s}^{-1}$ and was maintained throughout expiration. Tidal expiratory flowvolume loops generated with NEP were superimposed on those obtained during the preceding tidal breaths. If application of NEP did not result in increased flow, the subject was considered to have EFL. Three test breaths were performed for all subjects in both the sitting and supine positions, in random order. The pneumotachogram was continuously monitored during testing on the screen of the computer, and calibrations for flow and pressure were performed prior to each testing occasion.

EFL was classified according to the three-point EFL score [12], as not flow limited (NFL), flow limited in the supine position (FLsupine), or flow limited in both the seated and supine positions (FLseated). Reliability of the NEP technique was assessed in 20 randomly selected subjects with stable disease [11] by repeated measurement at their subsequent clinic visit.

Immediately following NEP measurements, IC was measured in the sitting and supine positions. Measurements were performed in the same order as NEP measurements with a turbine spirometer (Super Spiro; Micro Medical). The mean of three technically acceptable manoeuvres was recorded. Predicted IC values were calculated as the difference between predicted total lung capacity (TLC) and predicted FRC [13]. Standard spirometry was then performed [14] and results were compared with predicted values [15]. In subjects with CF, measurements were taken before and $5 \mathrm{~min}$ after administration of $300 \mu \mathrm{g}$ salbutamol via metered-dose inhaler. In 30 subjects with $\mathrm{CF}$, measurements of thoracic gas volume were obtained in a constant-volume whole-body plethysmograph (Medgraphics 1085D Series; Medical Graphics Corporation, Minnesota, MN, USA) in order to validate measures of IC; the measurements were expressed as \% predicted normal values [13].

Prior to NEP and lung function testing, subjects rated their degree of chronic dyspnoea using the modified Medical Research Council (MRC) scale [4].

\section{Statistical analysis}

Differences between groups were evaluated with univariate ANOVA and the Tukey test for multiple comparisons, or the Pearson's Chi-squared test for categorical variables. The strength of the relationships between MRC score and other variables were evaluated with the Spearman rank correlation coefficient. Variables with a p-value $\leqslant 0.1$ were included in an ordinal logistic regression analysis, with MRC score as the dependent variable [16]. Reliability of the three-point EFL score between testing occasions was evaluated using the kappa statistic [17]. Statistically significant differences were accepted at the level of $\mathrm{p}<0.05$.

\section{RESULTS}

Demographic data for the control and CF subjects are shown in table 1 . The two groups were well matched for age and sex but differed significantly in nutritional status and spirometric indices. In the CF group, FEV1 values ranged $17.3-91.5 \%$ pred. The study sample represented $64 \%$ of the total CF clinic population and there were no significant differences between the study sample and the clinic population in distribution of age or forced expiratory volume in one second (FEV1) \% pred. No subject with CF demonstrated significant reversibility of airflow obstruction on post-bronchodilator testing. Chronic dyspnoea was not reported by any control subject. In the CF group, MRC values ranged from 0 (none) to 4 (severe). None of the $\mathrm{CF}$ subjects reported chronic dyspnoea that was in the category of "very severe" $(\mathrm{MRC}=5)$.

EFL during tidal breathing was not present in any control subjects. In the CF group, EFL was present in 34 subjects $(33.3 \%)$. Sixteen subjects $(15.7 \%)$ were FLsupine and 18 subjects $(17.6 \%)$ were FLseated. All subjects who were flow limited in the sitting position were also flow limited in the supine position. Of the 20 subjects who were tested on two occasions, NEP scores were consistent in 18 subjects, resulting in a kappa of 0.82 and indicating excellent agreement [17].

Characteristics of the subjects with $\mathrm{CF}$, stratified according to the three-point EFL score, are shown in table 2. The FLseated subjects were older than those in the other two groups; however, there was no difference in nutritional status. FEV1 was lower in FLseated subjects compared with those who were FLsupine; the FLsupine group also had significantly reduced FEV1 compared with NFL CF subjects. However, variation was observed between individuals, as some patients with severely reduced FEV1 were NFL (fig. 1a). Subjects who were FLseated reported significantly higher MRC scores: seven out of the eight subjects who reported moderately severe or severe

\begin{tabular}{|c|c|c|}
\hline \multirow[t]{2}{*}{ TABLE 1} & \multicolumn{2}{|c|}{$\begin{array}{l}\text { Demographic data for cystic fibrosis and control } \\
\text { subjects }\end{array}$} \\
\hline & Controls & Cystic fibrosis \\
\hline \multicolumn{3}{|l|}{ Subjects n } \\
\hline Total & 20 & 102 \\
\hline Males & 10 & 58 \\
\hline Age yrs & $28.11 \pm 5.06$ & $29.22 \pm 7.31$ \\
\hline BMI $\mathbf{k g} \cdot \mathbf{m}^{-2}$ & $24.16 \pm 3.58$ & $21.40 \pm 2.96^{\star \star \star}$ \\
\hline FEV $1 \%$ pred & $107.75 \pm 12.04$ & $49.58 \pm 18.02^{\star \star \star}$ \\
\hline FVC \% pred & $108.30 \pm 12.31$ & $69.07 \pm 18.57^{\star \star \star}$ \\
\hline FEV1/FVC \% & $84 \pm 6$ & $61 \pm 13^{\star \star \star}$ \\
\hline MRC score & $0 \pm 0$ & $1.30 \pm 0.89^{\star \star \star}$ \\
\hline \multicolumn{3}{|c|}{$\begin{array}{l}\text { Data are presented as mean } \pm \text { SD, unless otherwise stated. BMI: body mass } \\
\text { index; FEV1: forced expiratory volume in one second; \% pred: \% predicted; } \\
\text { FVC: forced vital capacity; MRC: Medical Research Council. }{ }^{* \star *}: p<0.001 \\
\text { versus control. }\end{array}$} \\
\hline
\end{tabular}




\begin{tabular}{|c|c|c|c|}
\hline \multirow[t]{2}{*}{ TABLE 2} & \multicolumn{3}{|c|}{$\begin{array}{l}\text { Anthropometric and lung function data of } \\
\text { subjects with cystic fibrosis, stratified according } \\
\text { to the three-point expiratory flow-limitation score }\end{array}$} \\
\hline & NFL & FLsupine & FLseated \\
\hline Subjects $n$ & 68 & 16 & 18 \\
\hline$M / F$ subjects $n$ & $36 / 32$ & $7 / 9$ & $15 / 3^{*, \#}$ \\
\hline Age yrs & $28.2 \pm 6.6$ & $28.8 \pm 6.0$ & $33.1 \pm 9.8^{*}$ \\
\hline $\mathrm{BMI} \mathbf{k g} \cdot \mathrm{m}^{-2}$ & $21.5 \pm 3.2$ & $20.4 \pm 2.2$ & $21.8 \pm 2.7$ \\
\hline FEV $1 \%$ pred & $57.3 \pm 15.6$ & $40.5 \pm 11.6^{*}$ & $28.5 \pm 7.7^{\star, \#}$ \\
\hline FVC \% pred & $75.6 \pm 17.4$ & $62.4 \pm 13.8^{*}$ & $50.4 \pm 10.1^{*}$ \\
\hline FER & $0.65 \pm 0.10$ & $0.57 \pm 0.14^{*}$ & $0.48 \pm 0.11^{*}$ \\
\hline FEF25-75 \% pred & $30.5 \pm 17.1$ & $14.8 \pm 7.9^{*}$ & $10.4 \pm 5.0^{*}$ \\
\hline IC seated $\%$ pre & $84.6 \pm 19.4$ & $75.4 \pm 15.1$ & $61.4 \pm 16.9^{*}$ \\
\hline IC supine $\%$ prec & $87.1 \pm 20.0$ & $71.2 \pm 14.7^{*}$ & $57.3 \pm 16.9^{*}$ \\
\hline MRC score & $1.0 \pm 0.7$ & $1.4 \pm 0.6$ & $2.2 \pm 1.0^{*, \#}$ \\
\hline RV \% pred & $152 \pm 61$ & $176 \pm 40$ & $219 \pm 79 *$ \\
\hline FRC \% pred & $120 \pm 15$ & $112 \pm 14$ & $150 \pm 20^{*, \#}$ \\
\hline TLC \% pred & $97 \pm 8$ & $98 \pm 4$ & $105 \pm 8^{*}$ \\
\hline RV/TLC \% pred & $158 \pm 56$ & $174 \pm 57$ & $225 \pm 47^{*}$ \\
\hline \multicolumn{4}{|c|}{$\begin{array}{l}\text { Data are presented as mean } \pm \mathrm{SD} \text {, unless otherwise stated. NFL: not flow } \\
\text { limited; FLsupine: flow limited in the supine position; FLseated: flow limited in both } \\
\text { the seated and supine positions; M: male; F: female; BMI: body mass index; } \\
\text { FEV1: forced expiratory volume in one second; } \% \text { pred: \% predicted; FVC: } \\
\text { forced vital capacity; FER: forced expiratory ratio; FEF25-75\%: forced expiratory } \\
\text { flow rates between } 25-75 \% \text { of FVC; IC: inspiratory capacity; MRC: Medical } \\
\text { Research Council; RV: residual volume; FRC: functional residual capacity; TLC: } \\
\text { total lung capacity. } \because \text { : measured in } 12 \text { of the NFL subjects, seven of the FLsupine } \\
\text { subjects and } 11 \text { of the FLseated subjects. *: } p<0.05 \text { versus not flow-limited } \\
\text { group; } \#: p<0.05 \text { versus flow-limited supine group. }\end{array}$} \\
\hline
\end{tabular}

dyspnoea were in this group (fig. 1b). Fewer female than male subjects were FLseated (table 2), despite no significant difference in lung function or dyspnoea scores according to sex.

All subjects with CF showed reduced IC in the sitting position compared with control subjects (fig. 2a), even in the absence of EFL. Within the CF group, there was no difference between the NFL and FLsupine subjects in terms of IC in the sitting position; however, a significant reduction in seated IC was evident in FLseated subjects. In contrast, supine IC was reduced in both FLseated $(p=0.001)$ and FLsupine subjects $(p=0.03)$ compared with NFL subjects. A change in body position from sitting to supine resulted in a significant increase in IC in control subjects $(p<0.001$, supine versus seated IC) and NFL CF subjects $(p=0.01)$; however, the magnitude of this change was much smaller in those with CF (fig. 2b). The supine posture resulted in a small but significant decrease in IC in both FLsupine $(\mathrm{p}<0.001)$ and FLseated $(\mathrm{p}=0.01)$ subjects.

TLC was within normal limits for all three groups, with evidence of restrictive disease in only one NFL subject (TLC $84 \%$ pred). There was a small but significant increase in TLC in the FLseated group compared with the other subjects (table 2). In agreement with the results for IC, this group was also significantly more hyperinflated, as indicated by residual volume (RV)/TLC \% pred. There was a strong negative correlation between IC \% pred and RV/TLC \% pred across
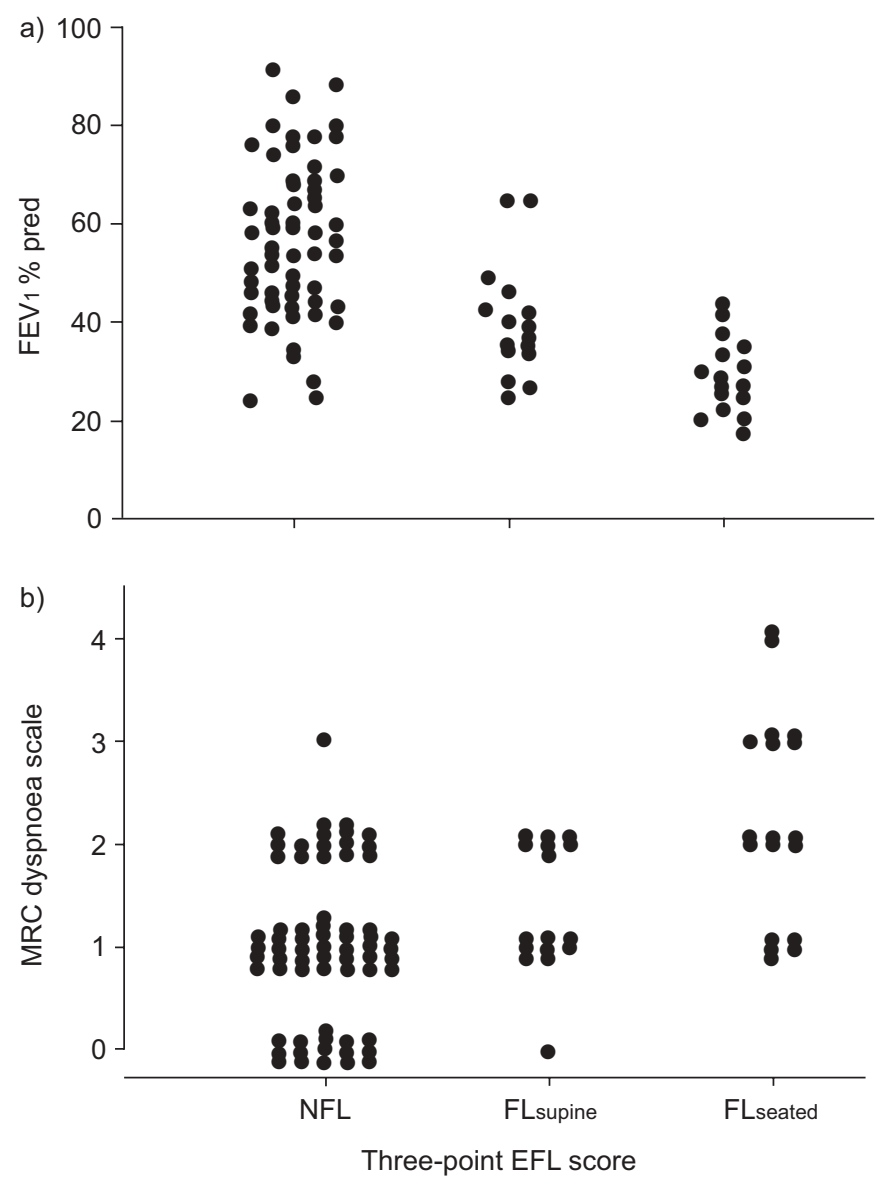

FIGURE 1. Relationship of three-point expiratory flow-limitation (EFL) score to a) forced expiratory volume in one second (FEV1) \% predicted and b) Medical Research Council (MRC) dyspnoea score. Each point represents data from an individual subject. NFL: not flow limited in the sitting or supine position; FLsupine: flow limited in the supine position only; FLseated: flow limited in the seated and supine positions.

all subjects $(\mathrm{r}=-0.82, \mathrm{p}<0.001)$. There was no significant difference in FEV1 \% pred, body mass index (BMI), age or MRC dyspnoea score between the subset of CF patients in whom lung volumes were measured and the remainder of the subjects from any of the three-point EFL categories.

Univariate regression identified six descriptive variables as potential predictors of MRC score: EFL score $\left(r_{S}=0.42\right.$, $\mathrm{p}<0.001) ; \mathrm{FEV} 1 \%$ pred $\left(\mathrm{r}_{\mathrm{S}}=-0.49, \mathrm{p}<0.001\right)$, IC $\%$ pred $\left(r_{S}=-0.35, p<0.001\right)$, age $\left(r_{S}=0.37, p=0.09\right)$, sex $\quad\left(r_{S}=0.31\right.$, $\mathrm{p}=0.1)$ and $\mathrm{BMI}\left(\mathrm{r}_{\mathrm{S}}=-0.49, \mathrm{p}<0.001\right)$. In the ordinal regression model where all six variables were included, the EFL score was the only significant predictor of chronic dyspnoea (table 3). This model accounted for $35 \%$ of the overall variance in dyspnoea score.

\section{DISCUSSION}

This study is the first to systematically examine the prevalence of EFL in a large $(n=102)$ cohort of adults with CF. The results show that tidal EFL was present in $33.3 \%$ of patients, where $17.6 \%$ were FLseated and $15.7 \%$ were FLsupine. Patients with EFL had a lower FEV1 and were older than NFL subjects. 

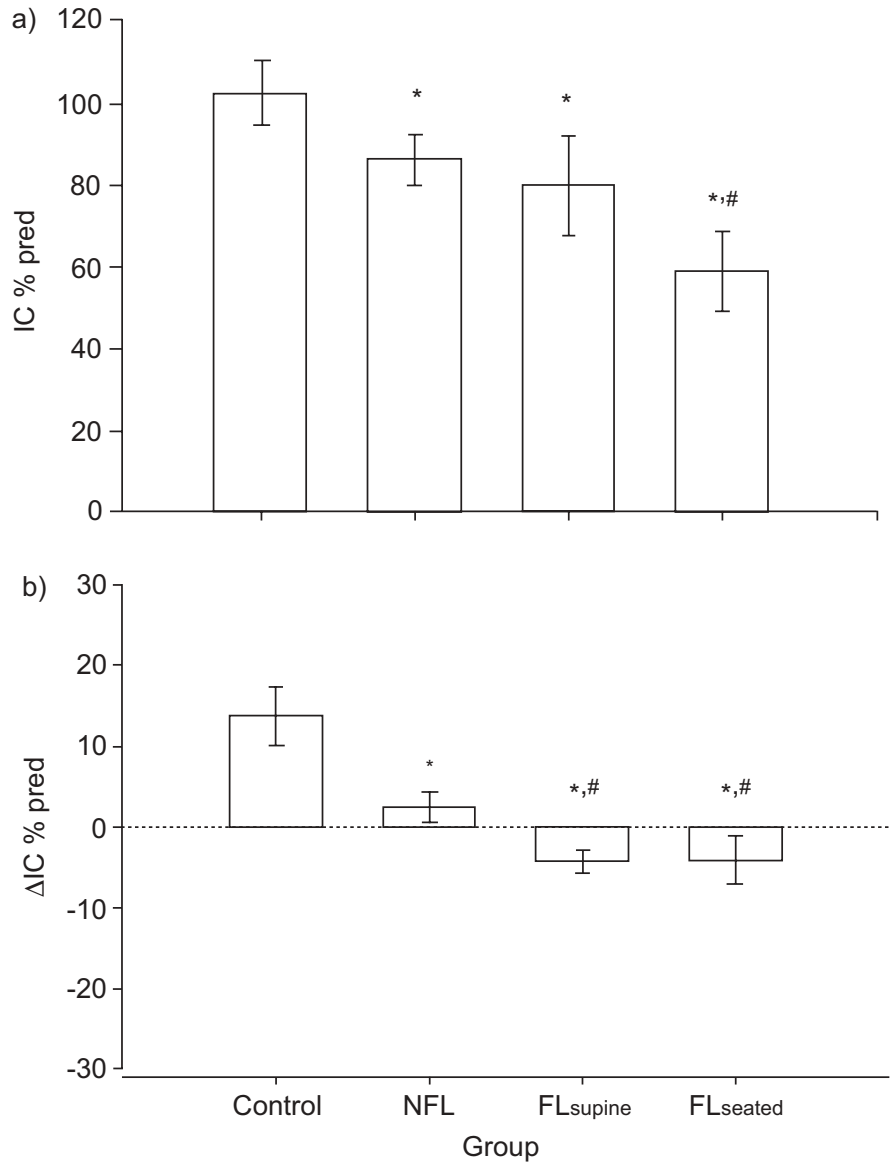

FIGURE 2. Relationship of expiratory flow limitation to a) inspiratory capacity $(I C)$ in the sitting position and b) change in IC $(\Delta \mathrm{IC})$ from sitting to supine position. Data are presented as mean and 95\% confidence interval. NFL: not flow limited in the sitting or supine position; FLsupine: flow limited in the supine position only: FLseated: flow limited in the seated and supine positions. ${ }^{*}: p<0.05$ versus control; $\#$ : $p<0.05$ versus NFL.

Those who were FLseated reported higher levels of chronic dyspnoea. The present study is the first to demonstrate the importance of EFL as a predictor of chronic dyspnoea in CF.

The present results are in contrast with those of a previous study, which concluded that the prevalence of EFL in CF was low, occurring in only three of 22 subjects (13.6\%) [5]. That study linked the occurrence of seated EFL with low BMI and FEV $1<30 \%$ pred. In the present study, the prevalence of EFL in the sitting position was higher, which may be related to the larger sample, lower mean FEV1 (50\% versus $61 \%$ pred) and older age of the subjects. In addition, the present study demonstrated that EFL also occurred when supine. The finding that all subjects who were flow limited in the sitting position were also flow limited when supine suggests that supine EFL is an earlier manifestation, as has previously been suggested in COPD [12]. The current authors did not demonstrate any link between EFL and nutritional status; however, the average BMI in the present group was higher than in the previous study $\left(21.4 \pm 3.0\right.$ versus $\left.17.9 \pm 2.7 \mathrm{~kg} \cdot \mathrm{m}^{-2}\right)$ [5]. A strong link was confirmed between FEV1 and EFL; however, the present study's larger group illustrated greater variation across

\begin{tabular}{|c|c|c|}
\hline TABLE 3 & $\begin{array}{l}\text { regressio } \\
\text { ch Counc }\end{array}$ & $\begin{array}{l}\text { f the } \\
\text { scale and }\end{array}$ \\
\hline \multirow[t]{2}{*}{ Covariate } & \multicolumn{2}{|c|}{ Model } \\
\hline & Estimate & SE \\
\hline \multicolumn{3}{|c|}{ Three-point EFL score } \\
\hline 1 & $-2.03^{*}$ & 0.75 \\
\hline 2 & -1.82 & 0.76 \\
\hline 3 & \multicolumn{2}{|c|}{ Reference category } \\
\hline BMI & -0.08 & 0.08 \\
\hline \multicolumn{3}{|l|}{ Sex } \\
\hline M & -0.77 & 0.43 \\
\hline $\mathrm{F}$ & \multicolumn{2}{|c|}{ Reference category } \\
\hline FEV $1 \%$ pred & -0.04 & 0.02 \\
\hline Age yrs & 0.03 & 0.03 \\
\hline IC \% pred sitting & -0.002 & 0.02 \\
\hline Pseudo $R^{2}$ & \multicolumn{2}{|c|}{$35 \%$} \\
\hline
\end{tabular}

EFL: expiratory flow limitation; BMI: body mass index; M: male; F: female; FEV1: forced expiratory volume in one second; \% pred: \% predicted; IC: inspiratory capacity. *: $p<0.05$

subjects. Whereas in the previous study all subjects with an FEV $1<30 \%$ pred exhibited tidal FL in the sitting position, in the present group six out of 17 subjects who had FEV1 $<30 \%$ pred did not demonstrate EFL in the sitting position. Conversely, seven subjects who were flow limited in the sitting position had an FEV $1>30 \%$ pred, ranging up to $43 \%$ pred. These findings are similar to those reported in COPD, where EFL in the sitting position has been reported in patients with an FEV1 of $\leqslant 50 \%$ pred [4].

The present study expands on previous work describing the presence of dynamic hyperinflation in CF across the range of disease severity $[5,6]$. However, the most significant reductions in IC were seen in flow-limited subjects and only in the body position in which EFL occurred (fig. 2), confirming a link between tidal EFL and dynamic hyperinflation [1]. It was postulated that reduced IC would contribute to chronic dyspnoea, and the present authors confirmed an association between these variables. However, this relationship did not remain significant in an ordinal regression model that also included EFL score. Greater levels of chronic dyspnoea were seen in the FLseated group and it is possible that dynamic hyperinflation has a more clinically significant impact when associated with EFL in the upright position, where most functional activities take place. An alternative explanation for the observed reduction in IC would be the presence of restrictive lung disease. This seems unlikely given that TLC was not reduced (table 2) and that the low prevalence of restrictive lung disease seen in this sample $(3 \%)$ is consistent with previous reports in CF [18]. However, as lung volumes could only be measured in a subgroup, it is not possible to completely discount this explanation.

Previous investigators have found that chronic dyspnoea in CF correlates poorly with standard measures of pulmonary 
function [19]. The present authors found dyspnoea to be significantly correlated with both EFL and FEV1 \% pred, and showed a stronger relationship between FEV1 and MRC score than has been previously reported [19]. This may occur secondarily to the strong relationship between FEV1 and IC seen in the present data $(\mathrm{r}=0.79, \mathrm{p}<0.001)$, as reduced IC during exercise results in higher levels of dyspnoea [20]. However, FEV1 was not a significant predictor of chronic dyspnoea in a model that also included EFL score, a finding which is similar to that reported in COPD [4].

The best model obtained was only able to account for one-third of the total variance in chronic dyspnoea. In contrast, in COPD patients, a model incorporating EFL and height was able to predict $58 \%$ of the variance in MRC score [4]. It is possible that MRC score is not a sensitive indicator of chronic dyspnoea in $\mathrm{CF}$; however, this seems unlikely as it has previously been shown to have a good relationship with exercise capacity [19]. It seems that additional and as yet unknown factors will be required to fully understand the mechanisms of chronic dyspnoea in CF.

Female subjects with $\mathrm{CF}$ were significantly less likely to exhibit EFL in the sitting position than males. This occurred despite no difference in severity of lung disease or degree of dyspnoea according to sex. The reason for this difference in severity of EFL is not clear. However, the finding that females have a similar degree of dyspnoea to males despite less EFL, suggests that there may be additional contributors to dyspnoea in females with CF. Higher levels of dyspnoea in females than males have been reported in both COPD [4] and subjects without lung disease [21], indicating that there may be a difference between the sexes in perception of respiratory effort which is unrelated to lung pathology.

The identification of EFL in CF is of great clinical interest if it suggests new therapeutic strategies. Increased expiratory flow rates are required for both exercise and airway clearance [9, $10]$, which are two of the cornerstones of management of CF [22]. The presence of EFL is likely to reduce the ability to generate high flow rates and may result in impaired performance [23], and excessive dyspnoea and fatigue during treatment [24]. It has been demonstrated that in patients with COPD, the deleterious effects of EFL can be offset with application of positive pressure [25]. This may provide a rationale for the use of positive pressure during exercise and chest physiotherapy in CF, strategies that have previously been described but lack supportive evidence $[24,26]$.

In conclusion, expiratory flow limitation occurred in $33.3 \%$ of patients with cystic fibrosis and is thus more prevalent than previously described. Flow-limited patients exhibit a lower forced expiratory volume in one second, older age and higher levels of chronic dyspnoea. Dynamic hyperinflation is strongly associated with expiratory flow limitation in both the sitting and supine positions; however, it is also present to a lesser degree in non-flow-limited patients. Expiratory flow limitation is an important predictor of chronic dyspnoea in cystic fibrosis, but a substantial proportion of the variance in chronic dyspnoea remains unexplained. Additional studies are required to elucidate other mechanisms underlying chronic dyspnoea in cystic fibrosis.

\section{ACKNOWLEDGEMENTS}

The authors would like to thank C. Tantucci for his invaluable assistance with the negative expiratory pressure technique and I. Gordon for his assistance with statistical analysis.

\section{REFERENCES}

1 Tantucci C, Duguet A, Similowski T, Zelter M, Derenne JP, Milic-Emil J. Effect of salbutamol on dynamic pulmonary hyperinflation in chronic obstructive lung disease patients. Eur Respir J 1998; 12: 799-804.

2 Bellemare F, Grassino A. Force reserve of the diaphragm in patients with chronic obstructive pulmonary disease. J Appl Physiol 1983; 55: 8-15.

3 Coussa ML, Guerin C, Eissa NT, et al. Partitioning of work of breathing in mechanically ventilated COPD patients. $J$ Appl Physiol 1993; 75: 1711-1719.

4 Eltayara L, Becklake MR, Volta CA, Milic-Emili J. Relationship between chronic dyspnea and expiratory flow limitation in patients with chronic obstructive pulmonary disease. Am J Respir Crit Care Med 1996; 154: 1726-1734.

5 Goetghebeur D, Sarni D, Grossi Y, et al. Tidal expiratory flow limitation and chronic dyspnoea in patients with cystic fibrosis. Eur Respir J 2002; 19: 492-498.

6 Braggion C, Polese G, Fenzi V, Carli MV, Pradal U, MilicEmili J. Detection of tidal expiratory flow limitation in infants with cystic fibrosis: a pilot study. Pediatr Pulmonol 1998; 25: 213-215.

7 Tauber E, Fazekas T, Eichler I, et al. Negative expiratory pressure: a new tool for evaluating lung function in children? Pediatr Pulmonol 2003; 35: 162-168.

8 Erwin WS, Zolov D, Bickerman HA. The effect of posture on respiratory function in patients with obstructive pulmonary emphysema. Am Rev Respir Dis 1966; 94: 865-872.

9 Regnis JA, Alison JA, Henke KG, Donnelly PM, Bye PT. Changes in end-expiratory lung volume during exercise in cystic fibrosis relate to severity of lung disease. Am Rev Respir Dis 1991; 144: 507-512.

10 van der Schans CP. Forced expiratory manoeuvres to increase transport of bronchial mucus: a mechanistic approach. Monaldi Arch Chest Dis 1997; 52: 367-370.

11 Cooper PJ, Robertson CF, Hudson IL, Phelan PD. Variability of pulmonary function tests in cystic fibrosis. Pediatr Pulmonol 1990; 8: 16-22.

12 Koulouris NG, Valta P, Lavoie A, et al. A simple method to detect expiratory flow limitation during spontaneous breathing. Eur Respir J 1995; 8: 306-313.

13 Quanjer PH, Tammeling GJ, Cotes JE, Pedersen OF, Peslin R, Yernault JC. Lung volumes and forced ventilatory flows. Report Working Party Standardization of Lung Function Tests, European Community for Steel and Coal. Official Statement of the European Respiratory Society. Eur Respir J Suppl 1993; 6: Suppl. 6, 5-40.

14 American Thoracic Society. Standardization of spirometry, 1994 update. American Thoracic Society. Am J Respir Crit Care Med 1995; 152: 1107-1136.

15 Knudson RJ, Lebowitz MD, Holberg CJ, Burrows B. Changes in the normal maximal expiratory flow-volume curve with growth and aging. Am Rev Respir Dis 1983; 127: 725-734.

16 McCullach P. Regression models for ordinal data (with discussion). J R Stat Soc 1980; Series B: 109-142. 
17 Portney L, Watkins M. Foundations of Clinical Research: Applications to Practice: 2nd Edn. Appleton and Lange, Connecticut, 1993; pp. 505-527.

18 Ries AL, Sosa G, Prewitt L, Friedman PJ, Harwood IR. Restricted pulmonary function in cystic fibrosis. Chest 1988; 94: 575-579.

19 de Jong $W$, van der Schans CP, Mannes GP, van Aalderen WM, Grevink RG, Koeter GH. Relationship between dyspnoea, pulmonary function and exercise capacity in patients with cystic fibrosis. Respir Med 1997; 91: 41-46.

20 Chetta A, Pisi G, Zanini A, et al. Six-minute walking test in cystic fibrosis adults with mild to moderate lung disease: comparison to healthy subjects. Respir Med 2001; 95: 986-991.

21 Killian KJ, Summers E, Jones NL, Campbell EJ. Dyspnea and leg effort during incremental cycle ergometry. Am Rev Respir Dis 1992; 145: 1339-1345.
22 Yankaskas JR, Marshall BC, Sufian B, Simon RH, Rodman D. Cystic fibrosis adult care: consensus conference report. Chest 2004; 125: 1S-39S.

23 Regnis JA, Donnelly PM, Robinson M, Alison JA, Bye PT. Ventilatory mechanics at rest and during exercise in patients with cystic fibrosis. Am J Respir Crit Care Med 1996; 154: 1418-1425.

24 Fauroux B, Boule M, Lofaso F, et al. Chest physiotherapy in cystic fibrosis: improved tolerance with nasal pressure support ventilation. Pediatrics 1999; 103: 1-9.

25 Smith TC, Marini JJ. Impact of PEEP on lung mechanics and work of breathing in severe airflow obstruction. J Appl Physiol 1988; 65: 1488-1499.

26 Henke KG, Regnis JA, Bye PT. Benefits of continuous positive airway pressure during exercise in cystic fibrosis and relationship to disease severity. Am Rev Respir Dis 1993; 148: 1272-1276. 